\title{
Title: Caught in the middle - research in the U.S.-Mexico border region
}

Authors: Taylor Edwards ${ }^{1 *}$, Michelle-María Early-Capistrán ${ }^{2}$, Myles B. Traphagen ${ }^{3}$, Martha M. Gomez-Sapiens ${ }^{4}$, Carolyn O’Meara ${ }^{5}$, America Lutz-Ley ${ }^{6}$, Héctor Vega Deloya ${ }^{7}$, Benjamin T. Wilder $^{8}$

\section{Affiliations:}

${ }^{1 *}$ University of Arizona Genetics Core, University of Arizona, 1657 E. Helen Street, room 111H Tucson, AZ 85721 USA; taylore@email.arizona.edu.

${ }^{2}$ Posgrado en Ciencias del Mar y Limnología, Universidad Nacional Autónoma de México, Av. Ciudad Universitaria 3000, Coyoacán, C.P. 04510, Mexico City, Mexico; earlycapistran@gmail.com.

${ }^{3}$ Wildlands Network, 300 University Avenue Suite 264, Tucson, Arizona USA; myles@,wildlandsnetwork.org.

${ }^{4}$ Department of Geosciences, University of Arizona, 1040 E. 4th Street, Tucson, AZ 85721 USA; gomezsap@email.arizona.edu.

${ }^{5}$ Instituto de Investigaciones Filológicas, Universidad Nacional Autónoma de México, Circuito Mario de la Cueva, Ciudad Universitaria, Coyoacán, 04510, Mexico City, Mexico; ckomeara@unam.mx.

${ }^{6}$ Center of Studies on Development, El Colegio de Sonora, Obregon 54, Hermosillo, México, 83000; alutz@.colson.edu.mx.

${ }^{7}$ Departamento de Historia y Antropología, Universidad de Sonora, Calle del Conocimiento, Edificio 9A, Centro, 83200, Hermosillo, Sonora, Mexico; hector.vega@unison.mx.

${ }^{8}$ University of Arizona, Desert Laboratory on Tumamoc Hill, 1675 W. Anklam Road, Tucson, Arizona 85719 USA; $\underline{\text { bwilder@email.arizona.edu. }}$

Abstract: The U.S.-Mexico border is a region of significant biological and cultural diversity that is of interest to scientists from a wide variety of disciplines. It is also an area of humanitarian crisis and contentious politics. U.S. and Mexican researchers who conduct fieldwork on both sides of the border are faced with ethical and logistical challenges in the course of their daily work. To better understand these complex dynamics, we review survey results that provide a window into the relationship between recent U.S. border policy and the attitudes and behavior of researchers working in the U.S.-Mexico border region. Researchers are faced with challenges ranging from difficulty in obtaining permits and accessing lands in border regions, to fear and intimidation along the militarized zones. Furthermore, in the midst of a humanitarian crisis, the research community is left caught in the middle when their work intersects with civil and human rights. 


\section{Main Text:}

The U.S.-Mexico border is a region of significant biological and cultural diversity (1) that has increasingly received international attention due to the humanitarian crisis and the increase in policies to militarize the border region, including the proposed building of a border wall. Researchers working in the U.S.-Mexico border region feel the effects of such policies on their ability to conduct scientific research (2). Policies affecting border regions can restrict access to areas and therefore reduce scientists' ability to collect comprehensive data, such as are necessary for conducting biodiversity inventories $(3,2)$. U.S. border policies are also among factors that influence exchange rates which affect the funding Mexican scientists receive when participating in collaborative grants, such as those awarded by the U.S. National Science Foundation and the Mexican National Council for Science and Technology (CONACYT) (4). Additionally, U.S. border policies can influence a Mexican scientist's decision to cross the border to collaborate with U.S. colleagues (4). Restrictions directly affecting the ability of researchers to collaborate over international boundaries can limit creativity and discovery (5), which could have long-term impacts, such as further separating countries' ability to understand each other and foster meaningful partnerships catalyzed by science, such as industrial innovation or ecological sustainability.

Due to an absence of data on the extent to which border politics affect international collaboration and researchers' ability to perform their jobs, a survey was conducted through the University of Arizona to better understand how border policies affect researchers, including college students, academic professionals, employees of non-profit organizations and federal and state agencies who work in the U.S.-Mexico border region. The online survey was distributed to the NextGeneration Sonoran Desert Researchers (N-Gen) Network; a multinational, multidisciplinary network of 807 individuals who conduct research and conservation throughout the Sonoran Desert (www.nextgensd.com). The intention of the study was to document the interactions that field researchers have with authorities and people crossing the U.S.-Mexico border, and the impacts that these interactions have on their ability to conduct research. The anonymous survey was offered in both English and Spanish and targeted researchers with at least 4 years of experience conducting fieldwork in the U.S.-Mexico border region (within 60 miles/100 km either north or south of the border).

\section{Survey Response}

The response rate for the survey, which included 59 questions, was 7\% $(n=59)$ of the total NGen Network. When assessed against the number of N-Gen member profiles with "borderlands" self-listed as "region" $(\mathrm{n}=130)$, response rate was $45 \% .59 \%(\mathrm{n}=35)$ of respondents were U.S. citizens, $36 \%(\mathrm{n}=21)$ were Mexican citizens, two individuals reported dual citizenship between U.S. and Mexico, and one reported dual citizenship between Mexico and "other". Survey respondents covered multiple disciplines: the most common was life sciences $(64 \%, \mathrm{n}=38)$, followed by physical sciences/engineering $(14 \%, n=8)$ and social sciences $(12 \%, n=7)$. The majority of respondents were affiliated with academic institutions $(59 \%, n=35)$, followed by those working with non-profit organizations $(17 \%, \mathrm{n}=10)$, with the remainder in government $(8 \%, \mathrm{n}=5)$, self-employed $(8 \%, \mathrm{n}=5)$, and jobs in other sectors. In addition to collecting detailed demographic information on respondents, the survey was divided into several sections, 
each addressing different topics related to safety, border crossings, disruptions to work, and interactions with border authorities and undocumented migrants.

\section{Do safety concerns influence research?}

In general, researchers reported feeling safe or fairly safe while working in the U.S.-Mexico border region $(81 \%, n=48)$, however this may reflect perceptual adjustments given the shifting contextualized circumstances; i.e. researchers make adjustments to their work by staying away from risky places. Respondents noted the importance of knowing the landowners and communities where they work. Many also reported that they have encountered situations where they felt their security was threatened while conducting fieldwork in the border region $(44 \%, \mathrm{n}=$ 26), occurring relatively equally within both countries. Experiences ranged from general fear, such as hearing gun shots, to petty and violent crimes, but the vast majority of these reported this occurring on less than $25 \%$ of trips $(87 \%, n=27)$. Most of the respondents reported that security concerns have influenced or altered their work plans in Mexico $(66 \%, n=39)$. In the U.S., respondents also reported safety concerns had affected their work, although less than in Mexico $(39 \%, n=23)$. Safety concerns in Mexico were primarily due to cartel and criminal activity, while concerns in the U.S. centered on direct intimidation or "uneasy" or threatening encounters with U.S. Border Patrol, private land owners, and militias.

\section{What restrictions are placed on researchers due to safety concerns?}

As a result of safety concerns, both Mexican and U.S. researchers have had their organization or employer place restrictions on working in Mexico $(37 \%, n=19)$. In most cases, this resulted in restricting access to specific areas or requiring additional paperwork or approval through their institution. Two U.S. government employees also reported adjusted protocols while working in the U.S., such as not allowing employees to wear their government uniform in the field and covering logos on work vehicles within a certain proximity to the border. Other work restrictions required employees to always work in pairs for safety. While these policies by employers may modify a researcher's work plans, other restrictions reported by researchers on international travel or attendance at conferences have consequences that affect a researcher's ability to collect data, collaborate and share ideas.

\section{How do interactions with border authorities affect research?}

While crossing into the U.S., roughly half $(53 \%, \mathrm{n}=31)$ reported having negative experiences with Border Patrol or other law enforcement, such as racial or ethnic profiling, discrimination based on religion, gender, age or sexual orientation, or excessive use of force. The majority of these $(80 \%, n=25)$ reported this had occurred infrequently (less than $25 \%$ of times crossing the border). Those reporting having had a negative experience were roughly equal between the total proportion of genders and U.S. and Mexican citizens participating in the survey. In contrast, negative interactions with U.S. Border Patrol or other U.S. law enforcement were greatly reduced when respondents were outside of border crossing points, e.g., in the field $(18 \%, \mathrm{n}=7)$. While crossing the border into Mexico, few respondents reported negative interactions with Mexican authorities $(17 \%, \mathrm{n}=9)$. 
Over half of researchers $(53 \%, \mathrm{n}=31)$ reported that concerns about U.S. border enforcement have influenced or altered their work plans within the last three years. They reported selecting field sites that minimize their interactions with Border Patrol, and many had concerns about being delayed due to a border shut down or frustration with travel plans due to long wait times when entering the U.S., sometimes exceeding three hours. Respondents reported that crossing the border takes longer now than it did in the past.

\section{What issues affect researchers the most?}

The primary issue that respondents reported as having "altered or disrupted" their ability to perform fieldwork in the border region was logistic complications crossing between the United States and Mexico, including delays and rejections $(60 \%, \mathrm{n}=23)$. This was followed by problems obtaining permits, such as visas, work permits, sampling permits, etc. $(56 \%, \mathrm{n}=22)$. One researcher reported that permit delays in shipping scientific equipment across the border had stalled their research for over a year. A quarter of respondents also reported that their work was affected by denial of access to locations $(26 \%, \mathrm{n}=10)$ and general fear and intimidation $(26 \%, \mathrm{n}$ $=10)$. Roughly half of respondents $(53 \%, \mathrm{n}=31)$ reported that these issues had increased in frequency or had caused greater disruption to their work within the last three years, with the biggest increase being in logistic complications while crossing the border $(61 \%, n=19)$.

\section{Research in the midst of a humanitarian crisis}

The U.S.-Mexico border is the site of a humanitarian crisis. The U.N. International Organization for Migration's Missing Migrants Project reports that over 1,900 migrant deaths occurred in the five-year period between 2014-2018 (6). It is not surprising to find that most researchers have encountered migrants while conducting fieldwork in the border region $(69 \%, n=40)$, although infrequently ( $88 \%$ reported less than $25 \%$ of the time). In situations of contact, migrants asked for assistance, such as food, water, or a ride a little over half of the time $(55 \%, \mathrm{n}=22)$. Researchers made a clear distinction between their willingness to offer food or water versus providing transportation. Researchers reported that recent prosecutions of humanitarian aid workers (7) have caused concern in performing their work in the border region $(53 \%, \mathrm{n}=31)$, and that this could influence their taking action to give aid to people crossing the border $(46 \%, \mathrm{n}$ $=26$ ). Survey respondents commented that they felt caught in the middle of an impossible situation where the fear of prosecution conflicts with their moral compass to help people in need. While the concerns exist, in most cases they are not sufficient to change the behavior of taking action that is viewed as moral or ethical by most respondents $(54 \%, \mathrm{n}=31)$.

\section{Synthesis}

While this study focused on the U.S.-Mexico borderlands, similar challenges apply to research conducted in other border regions, areas with high criminal activity, and conflict zones across the world $(8,9)$. Our results suggest that research is impacted by border policies in myriad ways, none of which are straightforward and mean different things to the diverse backgrounds represented by researchers in the region. Policies that make it harder to obtain permits or cross international borders have implications on a researchers' ability to perform their work and this has untold impacts on scientific discovery. Furthermore, in the midst of a humanitarian crisis, the 
research community is left caught in the middle when their work intersects with civil and human rights. Borders are inherently complex, geographically, biologically, and socially; we view the facilitation of collaborative, cross-border research anywhere as a foundation for building bridges between countries instead of walls. Importantly, societies have the right to enjoy the benefits of science. This requires that scientists are assured of the right to collaborate internationally, and to fulfill their functions without discrimination or fear of repression or prosecution, while guaranteeing the highest standards of ethical safeguards (10).

\section{References and Notes:}

1. Felger, R. S. \& Broyles, B. Dry borders: great natural reserves of the Sonoran Desert. (Univ of Utah Press 2007).

2. Peters, R. et al. Nature divided, scientists United: US-Mexico border wall threatens biodiversity and binational conservation. BioScience 68, 740-743 (2018).

3. Liu, J., Baeten, L. \& Verheyen, K. Biodiversity on international borders requires solid inventories. BioScience 69, 409 (2019).

4. Wade, L. Mexican scientists feel the Trump effect. Science Jan. 31 doi:10.1126/science.aal0682 (2017).

5. Wilder, B. T., O’Meara, C., Medel, A., Narchi, N. \& Aburto-Oropeza, O. The need for a next generation of Sonoran Desert researchers. Conserv Biol 27, 243-244 (2013).

6. Dionis, M. S. \& Dearden, K. "Missing Migrants Project data: A global overview; Americas United States-Mexico border" in Fatal journeys Volume 4; Missing migrant children Laczko, F., Black, J. \& Singleton, A. Eds, (IOM, Geneva, 2019) pp. 27-30.

7. Jordan, J. An Arizona teacher helped migrants. Jurors couldn't decide if it was a crime. The New York Times June 11 https://www.nytimes.com/2019/06/11/us/scott-warren-arizonadeaths.html (2019).

8. Linnell, J. D. C. et al. Border security fencing and wildlife: The end of the transboundary paradigm in Eurasia? PLoS Biol 14, e1002483 (2016).

9. Rodríguez Mega, E. Violent drug cartels stifle Mexican science. Nature 566, 303-304 (2019).

10. Shaheed, F. "The right to enjoy the benefits of scientific progress and its applications" in Report of the Special Rapporteur in the field of cultural rights United Nations General Assembly (A/HRC/20/26, United Nations, New York, 2012) doi: $\underline{10.1163 / 2210-}$ 7975 HRD-9970-2016149.

Acknowledgments: We think the N-Gen Board of Directors for their support of this study and the N-Gen community for their participation. We thank C. Dolan for her helpful comments in the preparation of this manuscript.

Funding: This project was conducted without financial support

Author contributions: Conceptualization, TE, BTW, MMEC, MBT, MMGS, ALL, HVD; Data curation, TE; Formal analysis, TE; Investigation, TE, BTW, MMEC, HVD; Methodology, TE, BTW, MMEC, MBT, MMGS, ALL; Project administration, TE, BTW, MMEC; Resources; TE, 
BTW; Visualization, ; Writing - original draft, TE, MMEC; Writing - review \& editing, TE, BTW, MMEC, MBT, MMGS, CO, HVD

Competing interests: Authors declare no competing interests

Data availability: All data from the survey, excluding personal comments to protect participant identity, can be found at the University of Arizona Research Data Repository (https://arizona.figshare.com/articles/Survey questions and responses for_Next-

Generation Sonoran_Desert researchers_Border_Survey/11977818). This study was approved by an Institutional Review Board responsible for human subjects research at The University of Arizona; IRB\# 1901268217. 